\title{
An Open Slot Antenna with Bandwidth Extension for WLAN/UWB Applications
}

\author{
Jing-Ya Deng, ${ }^{1,2}$ Tian-Qi Fan, ${ }^{1}$ Yan Zhang, ${ }^{2}$ Xiang Wen, ${ }^{2}$ Guo-Qiang Liu, ${ }^{3}$ and Li-Xin Guo \\ ${ }^{1}$ School of Physics and Optoelectronic Engineering, Xidian University, Xian, China \\ ${ }^{2}$ Institute of China Electronic System Engineering Corporation, Beijing, China \\ ${ }^{3}$ Beijing Institute of Spacecraft System Engineering, Beijing, China \\ Correspondence should be addressed to Jing-Ya Deng; jydeng2011@126.com
}

Received 11 July 2014; Revised 20 August 2014; Accepted 8 September 2014

Academic Editor: Renato Cicchetti

Copyright (C) 2015 Jing-Ya Deng et al. This is an open access article distributed under the Creative Commons Attribution License, which permits unrestricted use, distribution, and reproduction in any medium, provided the original work is properly cited.

\begin{abstract}
An open slot antenna with extended bandwidth for WLAN and UWB applications is proposed. The radiating structure is composed of a rectangular microstrip patch antenna exciting an L-shaped slot etched on the ground plane. The feed position is optimized to get better impedance match for the higher range of the UWB spectrum, while a step in the slot, realized in the ground plane, is employed to extend the lower limit of the bandwidth so as to cover the $2.4 \mathrm{GHz}$ WLAN frequency band. Using these design solutions the antenna bandwidth is successfully extended to $140 \%$ so as to cover both the WLAN and the UWB spectrum.
\end{abstract}

\section{Introduction}

In recent years, the wideband antennas have been widely used in wireless communication and radar systems. The development of high performance radio systems for multistandard local area networks $[1,2]$, the monitoring of the automotive transportation $[3,4]$, the remote screening of biological activities [5-7], and the analysis of the ground subsurface [810], as well as through-the-wall radar imaging [11], require the adoption of broadband antennas. In particular, the UWB communication systems have attracted considerable interest from both the academic and the industrial sectors, owing to their good characteristics, including low cost, low complexity, and extremely high data rate useful for short range communications. Being important components of UWB systems, the UWB antennas are nowadays a very hot topic frequently discussed in scientific papers. In the thousands of papers about UWB antennas, printed slot antennas are frequently considered due to their attractive characteristics such as the low profile, the wide bandwidth, the compact size, and the ease of manufacturing. A microstrip fed patch antenna with a quarter wave open slot etched on the ground plane was proposed in [12]. In this paper, a broadened bandwidth of about $94 \%$, which is much wider than that of the traditional patch antennas, but insufficient for the UWB applications, has been obtained. A rotated patch is introduced in [13] to enhance the bandwidth of the antenna to $3.1-10.6 \mathrm{GHz}$ so as to cover the UWB applications. T-shaped stub extended from the patch [14] and truncated corner of the patch [15] are also presented to increase the bandwidth. Some novel structures, such as dipolar planar radiating structures, are also studied for UWB systems. For example, a low-profile printed drop-shaped dipole antenna [16] was reported to obtain interesting radiative performances in both frequency and time domain. Specifically, such antenna can be adopted to realize compact array antennas. However, only few of the mentioned papers consider the potential applications of the antennas in the WLAN systems working in the $2.4-2.48 \mathrm{GHz}$ frequency band.

In this paper, a wideband microstrip patch antenna, integrating an open-ended L-shaped slot on the ground plane, for WLAN and UWB applications is proposed. The feed position is optimized to get better impedance matching for the higher frequencies of the UWB spectrum, while a step in the slot on the ground plane is employed to extend the lower limit of the frequency band to $2.4 \mathrm{GHz}$ WLAN band. The antenna performances are analyzed and discussed, while a prototype has been fabricated and measured. The obtained results show 


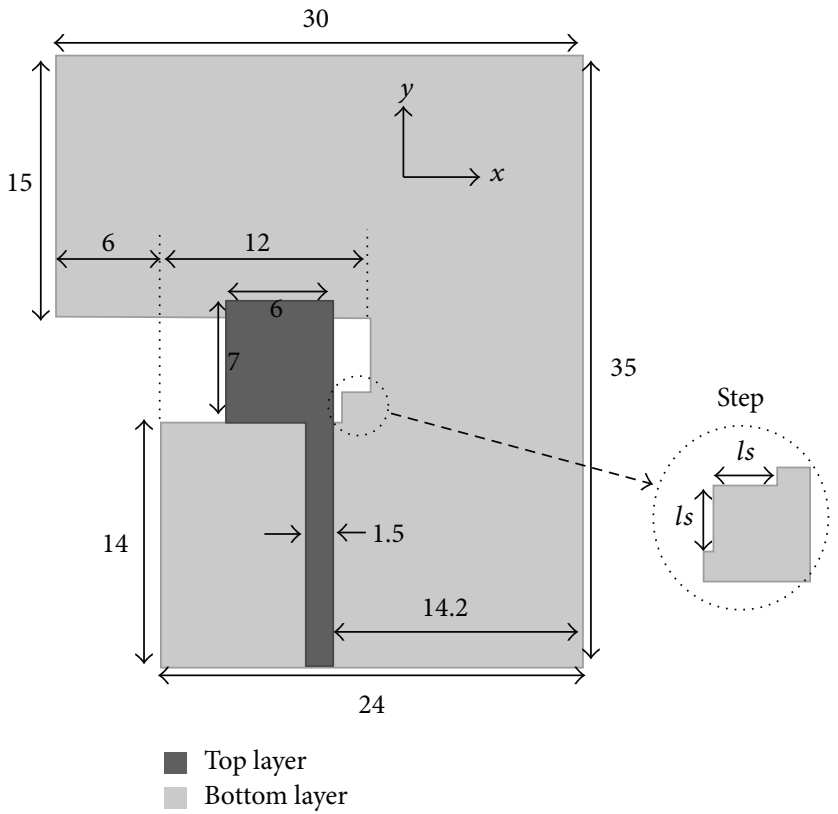

FIGURE 1: Geometry of the proposed antenna (all the geometrical dimensions are expressed in millimeter).

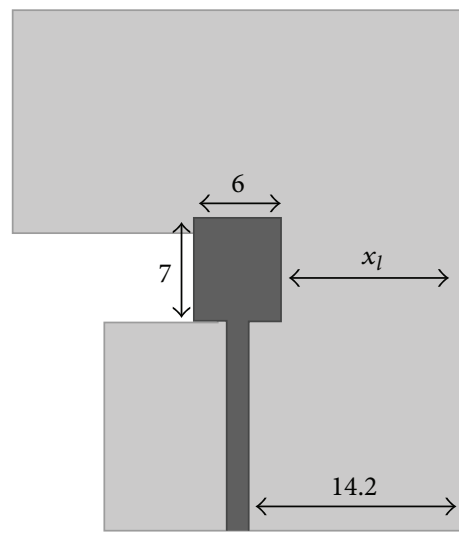

Antenna A

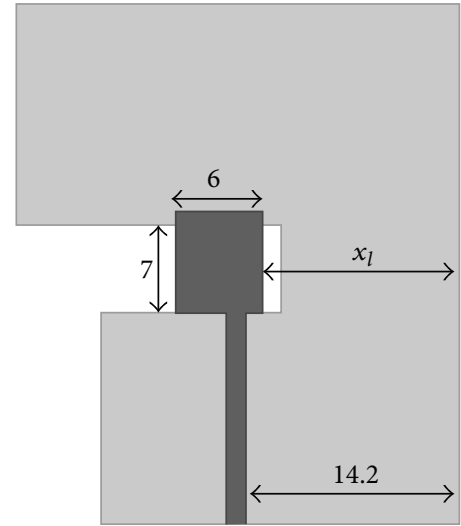

Antenna B

(b)

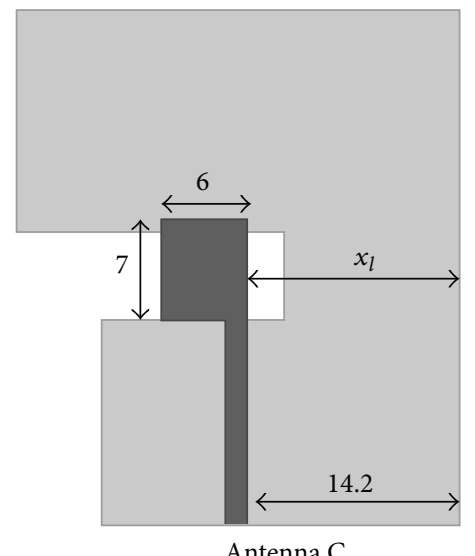

(c)

FIGURE 2: Design solutions adopted to excite the patch antenna.

that the bandwidth has been successfully broadened and that the proposed antenna is a good candidate for both WLAN and UWB systems.

\section{Design and Optimizations}

The geometry of the proposed antenna is shown in Figure 1. The antenna is printed on a low cost FR4 substrate having thickness of $1 \mathrm{~mm}$, relative permittivity of 4.6 , and loss tangent of 0.02 . The radiating structure is composed of a microstrip patch antenna and an asymmetrically slotted ground plane. The L-shaped slot etched on the ground plane has been employed to enlarge the antenna bandwidth.

The different design solutions adopted to excite the patch are shown in Figure 2, while the numerical simulations of the corresponding $S_{11}$ parameter are given in Figure 3. An EM simulator HFSS is used to optimize the geometry. In particular, a lumped port is set at the end of the microstrip line, while perfectly matched layers (PML) have been employed as absorbing boundary conditions to model the free-space environment. The design begins with antenna A shown in Figure 2, in which the feed position is located at the center of the radiating patch. Antenna A can cover the $2.35-6 \mathrm{GHz}$ frequency band with $S_{11}$ better than $-10 \mathrm{~dB}$, which is much wider than that of the traditional patch antenna, but it is insufficient for the UWB communications. To meet the bandwidth requirements of the UWB systems, the patch is moved, so the feed position is gradually transferred from the center of the patch up to its edge, as it is shown in antenna sketches $\mathrm{B}$ and $\mathrm{C}$ depicted in Figure 2. The 


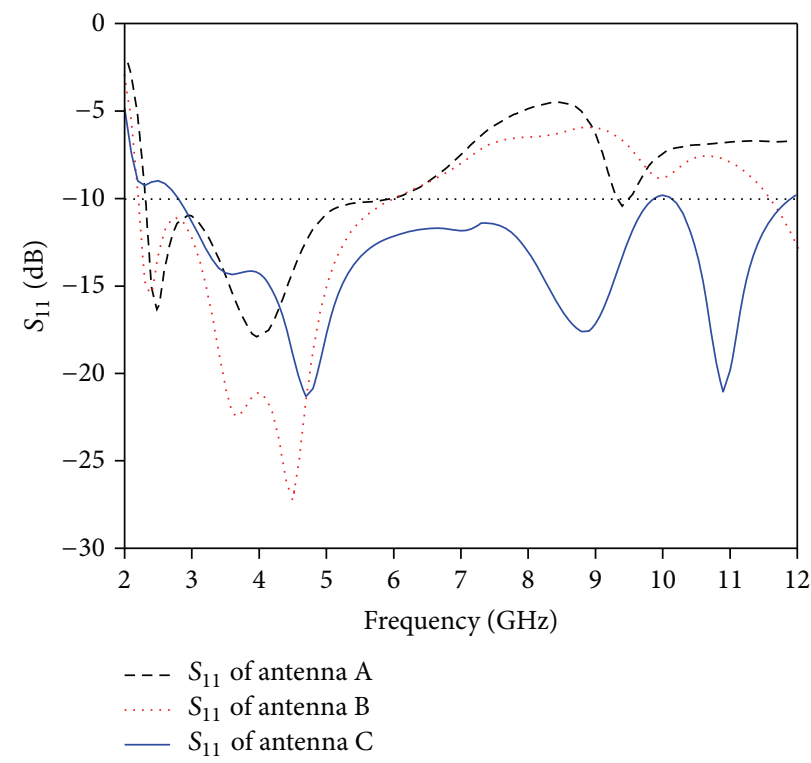

FIGURE 3: Magnitude of the scattering parameter $S_{11}$ versus frequency of the antennas depicted in Figure 2.
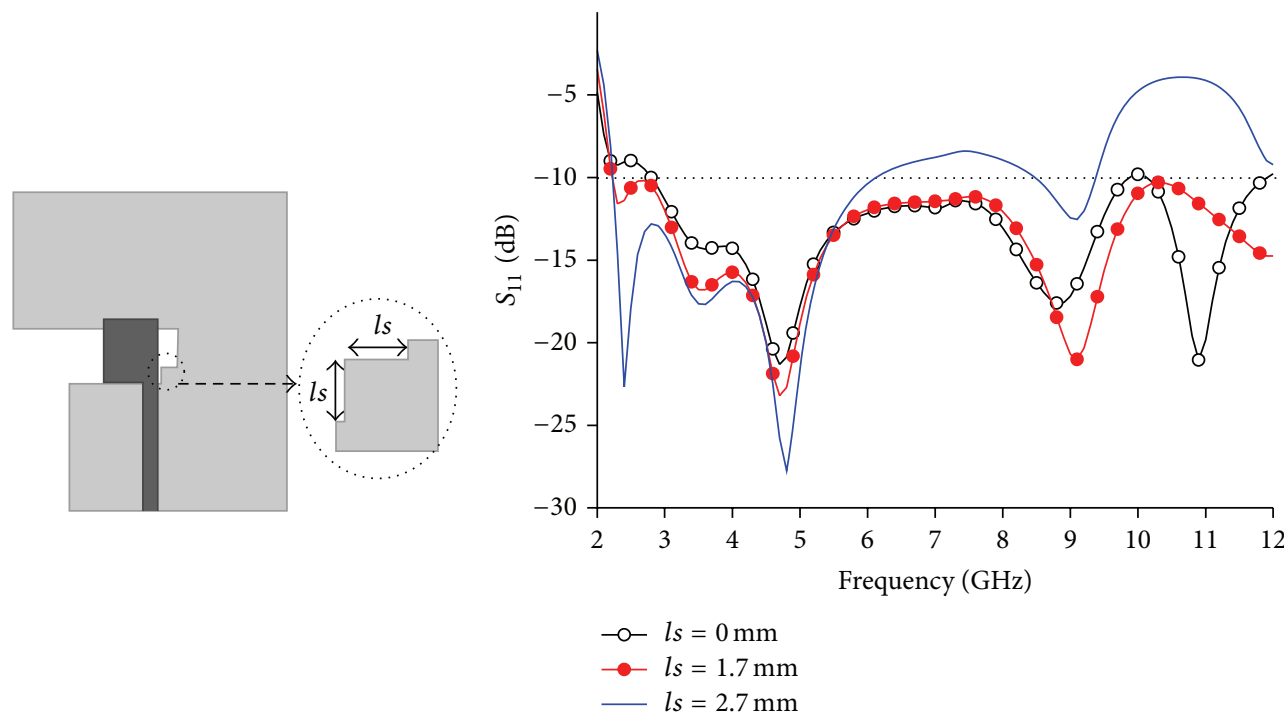

(a)

(b)

FIGURE 4: Magnitude of the scattering parameter $S_{11}$ versus frequency for different values of the geometrical parameter $l s$.

corresponding geometrical parameters of antennas A, B, and $\mathrm{C}$ are reported in Table 1. From Figure 3, it can be observed that the impedance matching at the higher frequencies of the UWB spectrum is improved during the adjustment. It should be noticed that the antennas depicted in Figure 2 have no step in the ground plane as instead it is present in the antenna shown in Figure 1.

The improvement of the performance of the parameter $S_{11}$ on high frequency, obtained by the movement of the feed position, worsens the impedance matching on the frequencies near $2.4 \mathrm{GHz}$. From Figure 3 it can be observed that antenna $\mathrm{C}$ can cover the entire UWB band with the parameter $S_{11}$ lower than $-10 \mathrm{~dB}$ from $2.8 \mathrm{GHz}$ up to $12 \mathrm{GHz}$,
TABLE 1: The key geometrical parameters of antennas A, B, and C in Figure 2.

\begin{tabular}{lccc}
\hline & Antenna A & Antenna B & Antenna C \\
\hline$x_{l}(\mathrm{~mm})$ & 12 & 13.1 & 14.2 \\
\hline
\end{tabular}

but in any case it is not suitable for the WLAN applications at $2.4-2.48 \mathrm{GHz}$. So, a step in the ground plane having length $l s$, as shown in Figure 1, is introduced in antenna C to improve the impedance matching at the lower frequencies. Figure 4 shows the antenna parameter $S_{11}$ for different values of the geometrical parameter $l s$. As it can be observed, the 


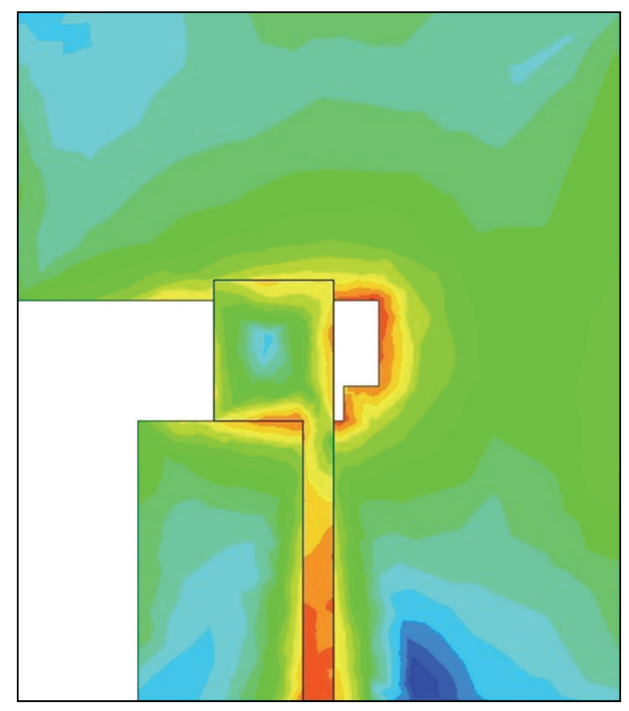

(a)

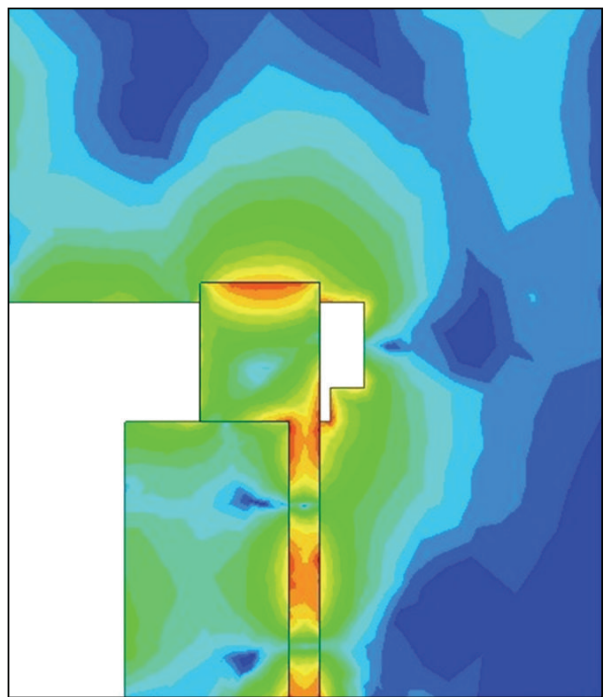

(c)

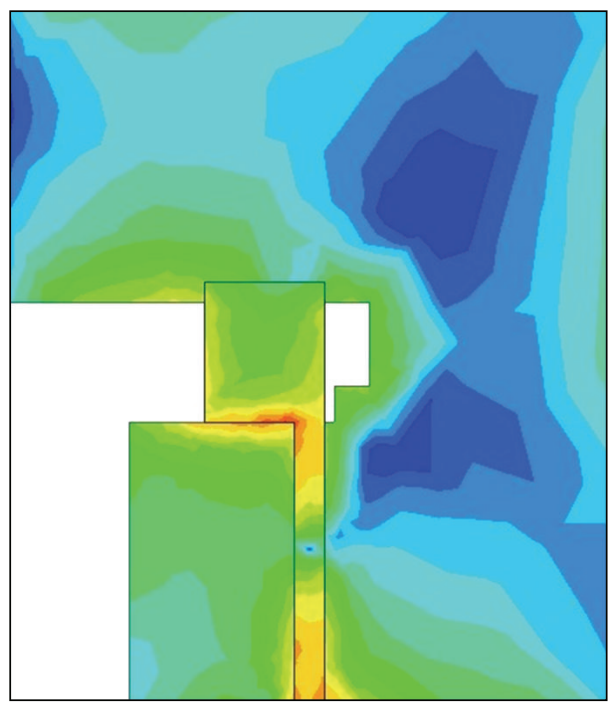

(b)

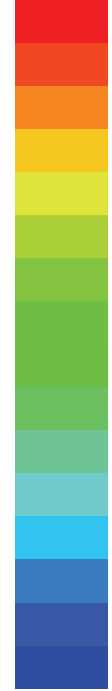

$1.5000 e+002$

$1.0487 e+002$

$7.3320 e+001$

$5.1261 e+001$

$3.5839 e+001$

$2.5056 e+001$

$1.7518 e+001$

$1.2247 e+001$

$8.5627 e+000$

$5.9865 e+000$

$4.1854 e+000$

$2.9262 e+000$

$2.0458 e+000$

$1.4303 e+000$

$1.0000 e+000$

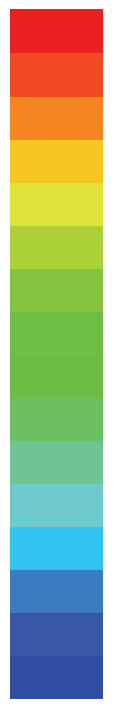

$1.5000 e+002$

$1.0487 e+002$

$7.3320 e+001$

$5.1261 e+001$

$3.5839 e+001$

$2.5056 e+001$ $1.7518 e+001$ $1.2247 e+001$ $8.5627 e+000$ $5.9865 e+000^{\circ}$ $4.1854 e+000$ $2.9262 e+000$ $2.0458 e+000$ $1.4303 e+000$ $1.0000 e+000$

FIGURE 5: Surface current distributions, (a) $2.4 \mathrm{GHz}$, (b) $5 \mathrm{GHz}$, and (c) $10 \mathrm{GHz}$.

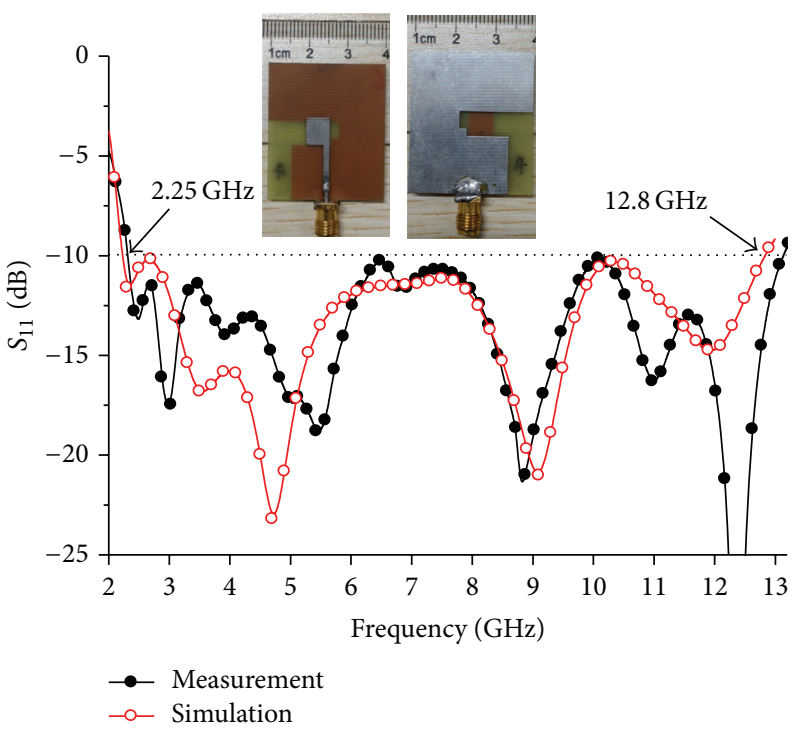

FIGURE 6: Magnitude of the scattering parameter $S_{11}$ versus frequency of the proposed antenna. 


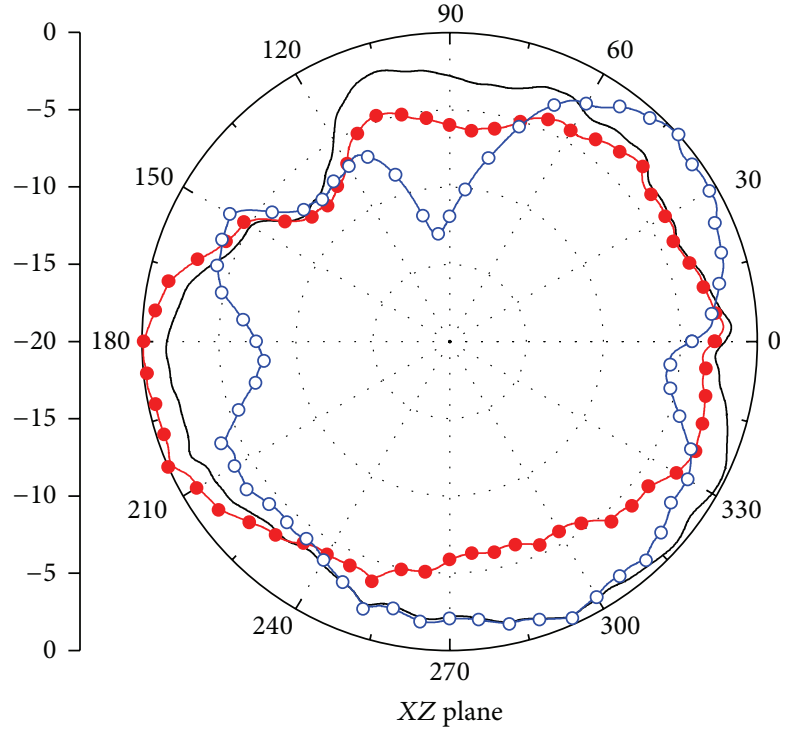

(a)

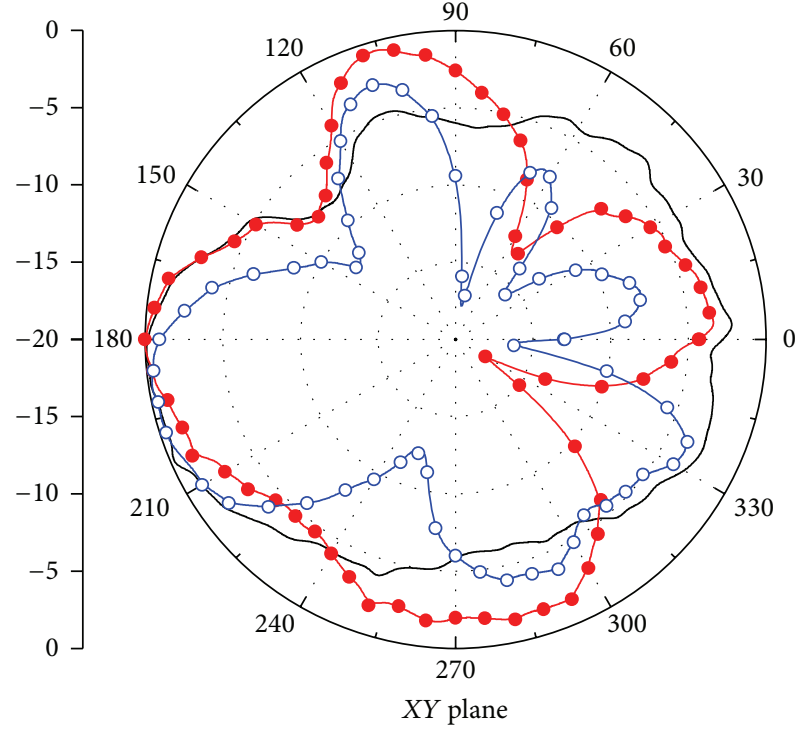

(b)

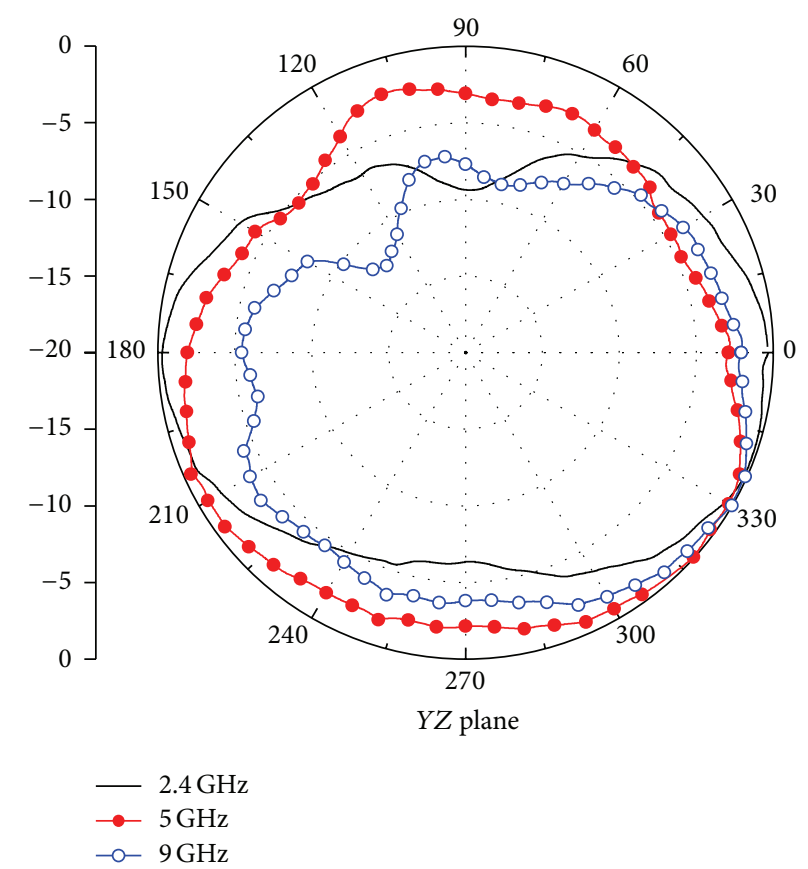

(c)

FIGURE 7: Radiation patterns of the proposed antenna.

impedance matching gets better at the lower frequencies, but it becomes worse at the higher frequencies when the parameter $l s$ exceeds $1.7 \mathrm{~mm}$. So, we choose the optimal value of $1.7 \mathrm{~mm}$ for $l s$. From the above considerations we can conclude that the step involved in the slotted ground plane plays an important role in the impedance matching.

To investigate about the radiation mechanisms governing the antenna behavior [17], the current distributions computed at $2.4,5$, and $10 \mathrm{GHz}$ are shown in Figure 5. From this figure it appears that the electromagnetic energy emissions at the lower frequencies $(2.4$ and $5 \mathrm{GHz})$ are due to the L-shaped open slot. Consequently, a step with a proper $l s$ value inserted in the slot can extend the current path on the ground plane near $2.4 \mathrm{GHz}$, so that the lower limit of the operation band can be extended to cover the WLAN frequency band. Finally, from Figure 5(c) it is evident that the antenna resonates on the fundamental mode of the microstrip patch near $10 \mathrm{GHz}$.

\section{Measurement Results}

The optimized antenna depicted in Figure 1, with $l s=$ $1.7 \mathrm{~mm}$, has been fabricated and measured. The frequency 


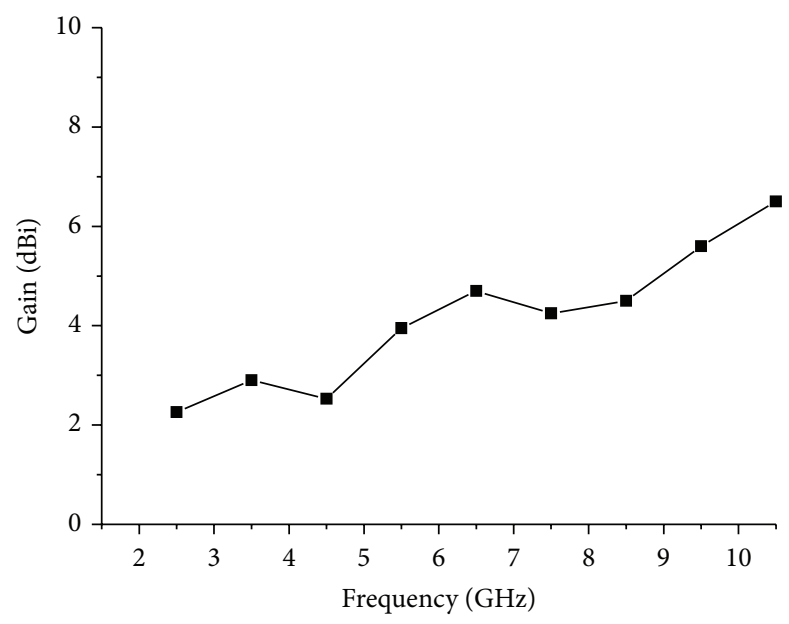

FIgURE 8: Gains of the optimal antenna.

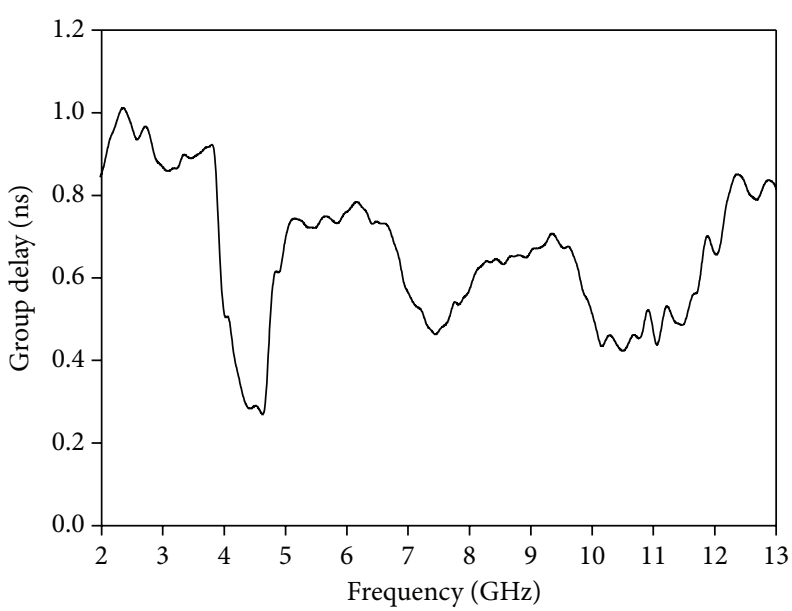

Figure 9: Group delay of the optimal antenna.

behaviors of the simulated and measured $S_{11}$ parameter are plotted in Figure 6. A good agreement between the two curves is observed. In this way, a frequency band between $2.25 \mathrm{GHz}$ and $12.8 \mathrm{GHz}$, which covers both the WLAN and the UWB frequency spectrums, is obtained. This means that the antenna bandwidth is successfully extended by moving the feed position of the radiating patch and using a step on the slotted ground plane. Figure 7 shows the measured radiation patterns of the optimized antenna at the frequencies of $2.4 \mathrm{GHz}, 5 \mathrm{GHz}$, and $9 \mathrm{GHz}$, respectively. The antenna radiation patterns in the $\mathrm{XZ}$ plane are not omnidirectional, especially at $9 \mathrm{GHz}$, due to the asymmetrical ground plane. The gain of the optimized antenna varies between 2.26 and $6.5 \mathrm{dBi}$ over the entire working band as reported in Figure 8 .

The group delay quantifies the pulse distortion and the phase linearity of the field radiated by the antenna in the far region, so it represents a very important parameter for the UWB communications. The group delay is measured by means of two identical antennas placed at a distance of $20 \mathrm{~cm}$, with the two antennas facing each other where the corresponding radiation patterns present their maximum.
The maximum measured value of the group delay is less than $1 \mathrm{~ns}$ as it is shown in Figure 9. This means that the phases are nearly linear in the far field region and almost no pulse distortion will be caused.

\section{Conclusion}

A microstrip patch antenna with frequency band ranging from $2.25 \mathrm{GHz}$ up to $12.8 \mathrm{GHz}$, suitable to cover the WLAN and UWB applications, has been presented. The bandwidth has been extended to $140 \%$ by optimizing the feed position of the patch and realizing a step on the slotted ground plane. The measured results show that the optimized antenna can be used successfully for both the WLAN and the UWB communication systems.

\section{Conflict of Interests}

The authors declare that there is no conflict of interests regarding the publication of this paper. 


\section{Acknowledgments}

This work was supported by the National Natural Science Foundation of China (Grants nos. 61471280 and 61225002), the Specialized Research Fund for the Doctoral Program of Higher Education of China (no. 20130203120022), and the China Postdoctoral Science Foundation and Fundamental Research Funds for the Central Universities of China (nos. 7214572701 and 7214572706 ).

\section{References}

[1] R. A. Bhatti, Y. T. Im, and S. O. Park, "Compact PIFA for mobile terminals supporting multiple cellular and non-cellular standards," IEEE Transactions on Antennas and Propagation, vol. 57, no. 9, pp. 2534-2540, 2009.

[2] S.-Y. Suh and S. Ooi, "Challenges on multi-radio antenna system for mobile devices," in Proceedings of the IEEE Antennas and Propagation Society International Symposium (AP-S '07), pp. 1221-1224, Honolulu, Hawaii, USA, June 2007.

[3] J. Li and T. Talty, "Channel characterization for ultra-wideband intra-vehicle sensor networks," in Proceedings of the Military Communications Conference (MILCOM '06), pp. 1-5, October 2006.

[4] W. Xiang, Y. Huang, and S. Majhi, "The design of a wireless access for vehicular environment (WAVE) prototype for intelligent transportation system (ITS) and vehicular infrastructure integration (VII)," in Proceedings of the 68th Semi-Annual IEEE Vehicular Technology Conference (VTC '08-Fall), pp. 1-2, Calgary, Canada, September 2008.

[5] I. Oppermann, L. Stoica, A. Rabbachin, Z. Shelby, and J. Haapola, "UWB wireless sensor networks: UWEN—a practical example," IEEE Communications Magazine, vol. 42, no. 12, pp. S27-S32, 2004.

[6] M. Klemm and G. Troester, "Textile UWB antenna for wireless body area network," IEEE Transactions on Antennas and Propagation, vol. 54, no. 11, pp. 3192-3197, 2006.

[7] P. Bernardi, R. Cicchetti, S. Pisa, E. Pittella, E. Piuzzi, and O. Testa, "Design, realization, and test of a UWB radar sensor for breath activity monitoring," IEEE Sensors Journal, vol. 14, no. 2 , pp. 584-596, 2014.

[8] X. Zhuge, T. G. Savelyev, A. G. Yarovoy, and L. P. Ligthart, "Subsurface imaging with UWB linear array: evaluation of antenna step and array aperture," in Proceedings of the IEEE International Conference on Ultra-Wideband (ICUWB '07), pp. 66-70, September 2007.

[9] M. Soliman and Z. Wu, "Design, simulation and implementation of UWB antenna array and it's application in GPR systems," in Proceedings of the 2nd European Conference on Antennas and Propagation (EuCAP '07), p. 87, November 2007.

[10] A. A. Lestari, A. G. Yarovoy, and L. P. Ligthart, "Adaptive wire bow-tie antenna for GPR applications," IEEE Transactions on Antennas and Propagation, vol. 53, no. 5, pp. 1745-1754, 2005.

[11] C. Liebe, A. Gaugue, X. Zhao, J. Khamlichi, and M. Menard, "A through wall UWB RADAR with mechanical sweeping system," in Proceedings of the 39th European Microwave Conference (EuMC '09), pp. 1634-1637, Rome, Italy, 2009.

[12] W. S. Chen, "Broadband design of a small non-symmetric ground $\lambda / 4$ open slot antenna with small size," IEEE Antennas and Propagation Society International Symposium, pp. 25632566, 2006.
[13] K. Song, Y.-Z. Yin, S.-T. Fan, Y.-Z. Wang, and L. Zhang, “Open L-slot antenna with rotated rectangular patch for bandwidth enhancement," Electronics Letters, vol. 45, no. 25, pp. 1286-1288, 2009.

[14] K. Song, Y. Z. Yin, X. B. Wu, and L. Zhang, "Bandwidth enhancement of T-shaped stub," Microwave and Optical Technology Letters, vol. 52, no. 2, pp. 390-393, 2010.

[15] K. Song, Y.-Z. Yin, H.-H. Xie, S.-L. Zuo, and D. Xi, "A cornertruncated patch scheme of bandwidth enhancement for open slot antenna," in Proceedings of the International Symposium on Signals, Systems and Electronics (ISSSE '10), vol. 2, pp. 1-3, Nanjing, China, September 2010.

[16] G. Cappelletti, D. Caratelli, R. Cicchetti, and M. Simeoni, "A low-profile printed drop-shaped dipole antenna for wideband wireless applications," IEEE Transactions on Antennas and Propagation, vol. 59, no. 10, pp. 3526-3535, 2011.

[17] D. Caratelli, R. Cicchetti, G. Bit-Babik, and A. Faraone, "Circuit model and near-field behavior of a novel patch antenna for WWLAN applications," Microwave and Optical Technology Letters, vol. 49, no. 1, pp. 97-100, 2007. 

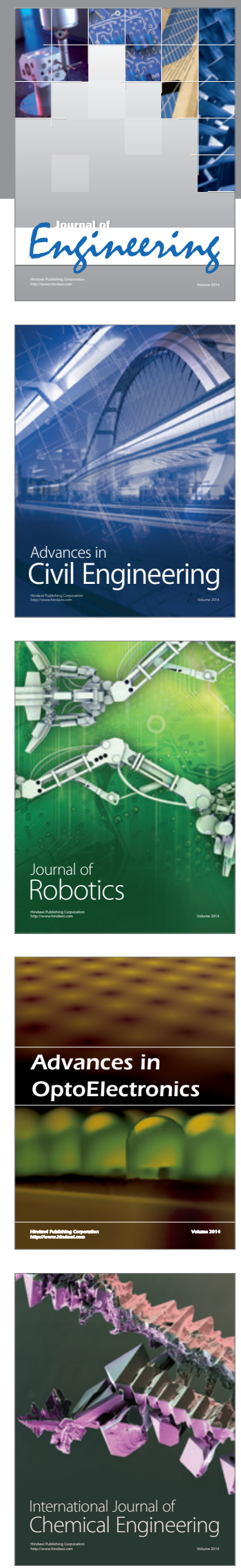

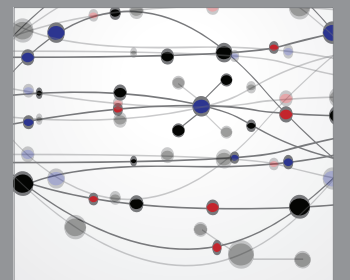

The Scientific World Journal
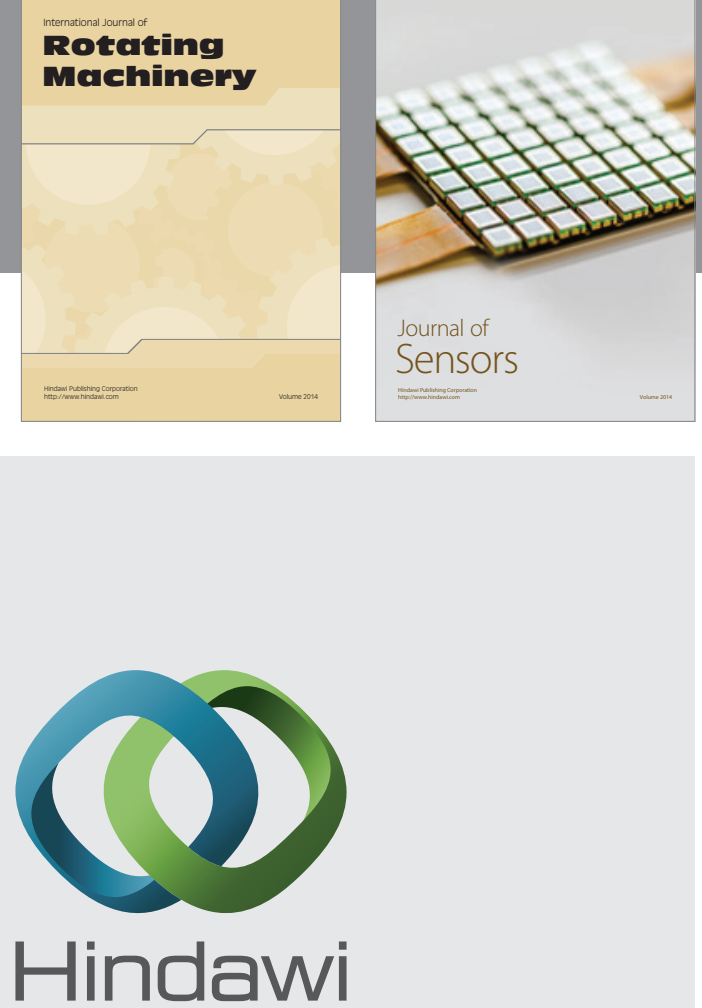

Submit your manuscripts at http://www.hindawi.com
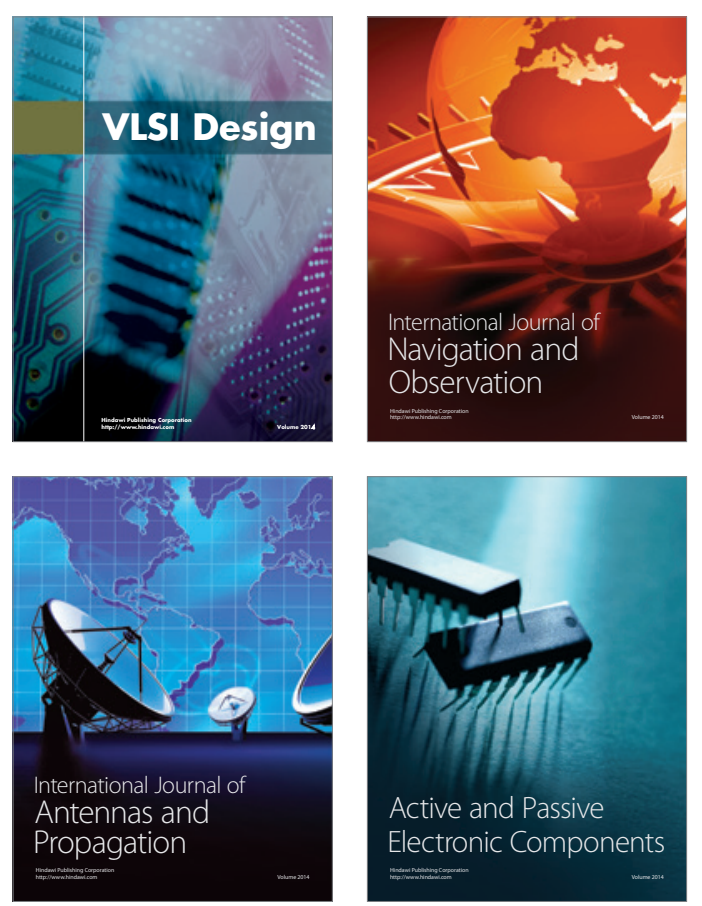
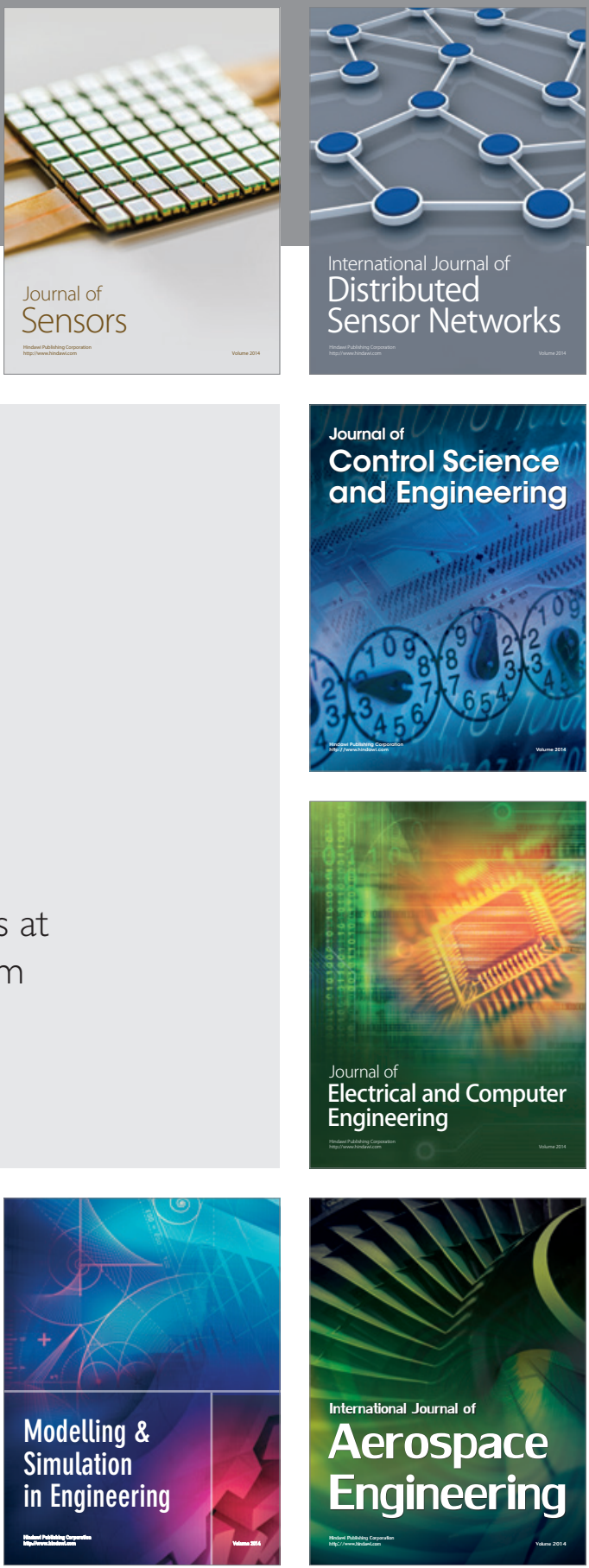

Journal of

Control Science

and Engineering
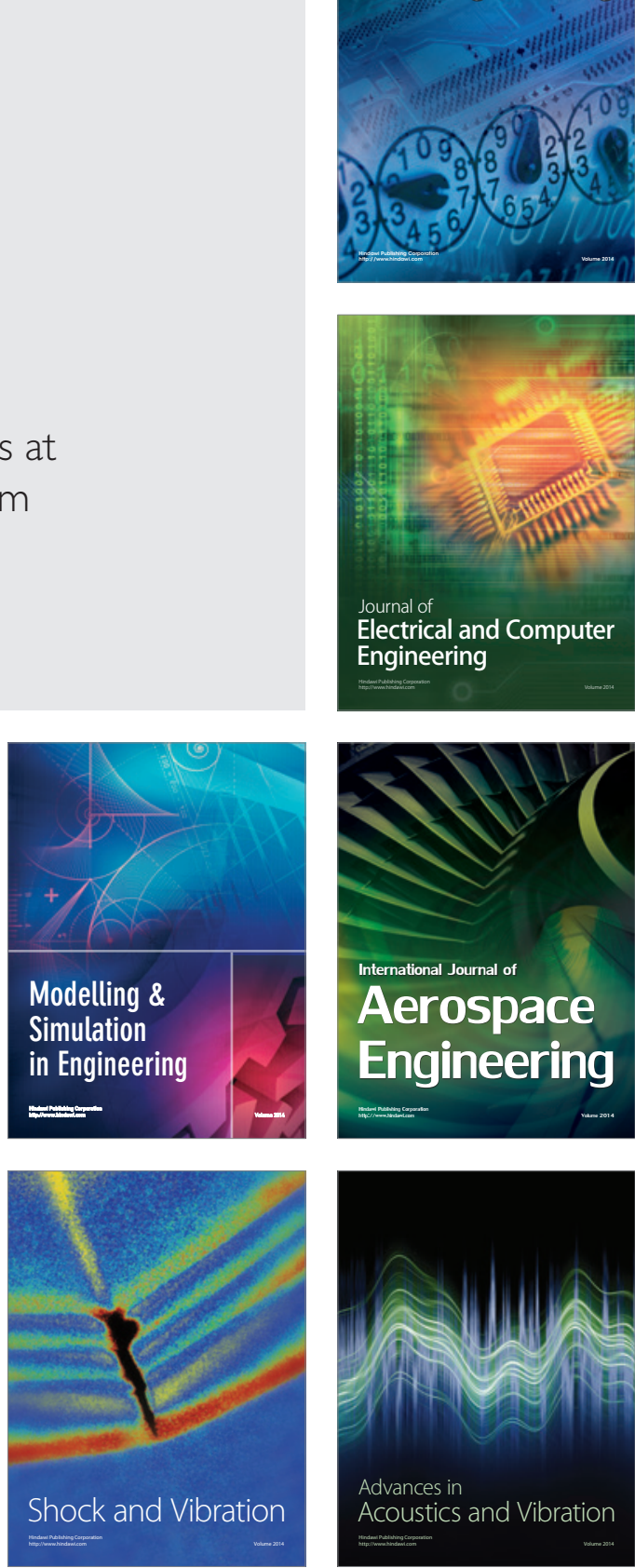